\title{
Structure and activities of Pharmacy and Therapeutics Committees among Public Hospitals in South Africa; findings and implications
}

\author{
Moliehi Matlala1, Andries GS Gous ${ }^{1}$, ${ }^{B}$ Brian Godman ${ }^{2,3}$, and Johanna C Meyer ${ }^{1}$ \\ ${ }^{1}$ School of Pharmacy, Sefako Makgatho Health Sciences University, Molotlegi Street, Ga-Rankuwa, \\ Pretoria, 0204. Emails: moliehi.matlala@smu.ac.za; andries.gous@smu.ac.za; \\ hannelie.meyer@smu.ac.za \\ 2Strathclyde Institute of Pharmacy and Biomedical Sciences, University of Strathclyde, Glasgow, \\ United Kingdom. Email: Brian.godman@strath.ac.uk \\ ${ }^{3}$ Department of Laboratory Medicine, Division of Clinical Pharmacology, Karolinska Institutet, \\ Karolinska University Hospital Huddinge, Stockholm, Sweden. Email: Brian.Godman@ki.se
}

\begin{abstract}
*Author for correspondence: Brian Godman, Division of Clinical Pharmacology, Karolinska Institute, Karolinska University Hospital Huddinge, SE-141 86, Stockholm, Sweden. Email:

Brian.Godman@ki.se. Telephone: +46 8 58581068. Fax: +46 859581070 and Strathclyde Institute of Pharmacy and Biomedical Sciences, University of Strathclyde, Glasgow G4 ORE, United Kingdom. Email: brian.godman@strath.ac.uk.

\section{(Accepted for publication - Expert Review of Clinical Pharmacology - Please keep CONFIDENTIAL)}

Key words: Pharmacy and Therapeutic Committees; hospitals; rational use of medicines; pharmacovigilance; South Africa

\begin{abstract}
Introduction: The WHO identified Pharmacy and Therapeutics Committees (PTCs) as a pivotal model to promote rational medicine use in hospitals. This matches a key South African (SA) government objective to establish PTCs in all hospitals to ensure rational, efficient and cost-effective use of medicines. However, documentation on the functionality of PTCs in public hospitals in SA is limited. This study aimed to address this. Methods: A 3-phased mixed methods approach involving questionnaires, observations of PTC meetings and semi-structured interviews. The findings were converged during the interpretation phase. Results: Most professionals were represented in the PTCs, with variations across hospitals. Membership of PTCs included a pharmacist, who in the majority of cases was the secretary. PTC activities included dissemination of decisions (100\%) and formulary management (89.5\%). However, reporting of ADRs and medication errors was typically poor at all hospital levels. Lack of expertise of pharmacoeconomic analysis and evidence-based decision-making in formulary management was identified as a key challenge in formulary management. Conclusion: Future programmes should strengthen PTCs in specialised aspects of formulary management. Further training in the principles of pharmacovigilance is needed at all levels to enhance ADR reporting, as well as to ensure compliance with both $\mathrm{WHO}$ and provincial guidelines.
\end{abstract}

\section{Introduction}

The concept of a pharmacy and therapeutics committee (PTC), also referred to as a drug and therapeutics committee (DTC), has been known for decades. However, this committee has become substantially more important in recent years with the continued launch of new high cost medicines, constrained budgets, and the need to ensure unbiased information for physicians when faced with pressures from pharmaceutical companies [1-8]. The beneficial effect of PTCs in monitoring and promoting the quality use of medicines, and containing costs in hospital and other institutional settings, has been generally accepted in developed countries $[9,10]$. This has resulted in for instance DTCs included in the law in Sweden, with each region in Sweden having at least one DTC [11]. However, PTCs either do not exist, or they do not work effectively, in many developing countries $[9,12,13]$. This leads to the irrational use of medicines along with other factors including inadequate training of health staff, lack of continuing education and supervision, lack of updated, reliable, unbiased drug information and lack of auditing and feedback of prescribing habits. Irrational and inappropriate use of medicines can lead to increased hospital admissions and prolonged hospital stay, subsequently increasing the cost of healthcare [14]. Effective, safe and economic medicines 
have to be selected, used and monitored, to ensure high quality therapy at an acceptable price for as many people as possible $[2,15,16]$.

The role of PTCs in improving the use of medicines in the community and hospitals is advocated by the World Health Organisation [17], and decisions surrounding the management of a formulary system should be based on evidence-based principals as well as economic factors to enhance optimal care [18]. The base from which members of PTCs can be recruited has widened over time as formularies have evolved [10]. A PTC can now include representatives from administration, quality assurance groups, and other healthcare professionals and also from user organisations [19]. Overall, pharmacists, nurses and the main medical specialists are typically represented in PTCs [14, 19-22].

There are many possible functions of a PTC, with a key responsibility being to manage the formulary system $[18,23,24]$. The PTC must decide which of these functions to undertake as a priority, which may depend on local capacities and structures [23].

South Africa published its National Drug Policy (NDP) in 1996, with one of its objectives being to establish PTCs in all hospitals in the country to ensure the rational, efficient and cost effective supply and use of medicines [25]. To date, we believe no studies have been performed that have addressed the composition, functions, and drug selection procedures in PTCs in public hospitals in South Africa. However, guidelines have been published both regionally and nationally to try and enhance the rational use of medicines in South Africa including guidelines on provincial PTC activities [24]. Consequently, this study aimed to describe PTC structures, activities and the medicine selection process among public sector hospitals in South Africa to provide a basis for future recommendations.

\section{Materials and methods}

An exploratory, mixed-methods study with a triangulation design was undertaken. Qualitative and quantitative data were collected and analysed separately, but sequentially in three phases, with priority given to qualitative data.

South Africa's health care system is structured according to four levels of care and referral. Primary health care $(\mathrm{PHC})$ is the first level, delivered through the District Health System. Health care services are offered at PHC clinics and community health care centers, with pharmaceutical services being managed by district pharmacies. Support and referral for health care services at this level of care are provided by district hospitals. The second level of care is provided by regional hospitals, from where referral can take place to tertiary (academic) hospitals. Central hospitals offer the highest (fourth) level of care with specialized hospitals proving care to specialized groups of patients such as at psychiatric hospitals. Pharmaceutical services at hospital level are offered by hospital pharmacies with provincial pharmaceutical services (Provincial PTCs) overseeing all pharmacy related activities at all levels of health care $[26,27]$.

The study was conducted among public hospitals in the Guateng Province of South Africa. This province was chosen as a representative Province for PTC activities with the findings forming the basis of future recommendations. At the time of the study, the Gauteng Province had five district pharmacies, 13 district hospitals, nine regional hospitals and four tertiary (academic) hospitals $(n=31)$. According to the norms and standards for quality service delivery in South Africa, each level of the pharmaceutical services is required to have its own PTC [27]. Specialized hospitals were excluded from this study, as most did not have active PTCs.

Phase 1 entailed a questionnaire survey being sent to 30 pharmacy managers, who were the pharmacy managers of 26 hospitals and five district pharmacies in the Province, One of the academic hospitals was excluded from the study as it served as the pilot site for this study. Pharmacy managers were targeted for this study as pharmacists were identified as playing an important role in most PTCs [13]. The questionnaire was developed based on a provincial circular letter [26], which outlined the structure, activities, objectives and medicine selection process for Gauteng Province PTCs. The questionnaire consisted of 13 questions contained in the areas of structure, activities and challenges with keeping PTCs active. Two of the questions contained 21 sub- questions which required yes or no response to pre-coded categories. A question regarding challenges encountered by pharmacists in keeping the PTC active was open ended (Appendix 1). Questionnaires were either emailed or faxed to the pharmacists. Responses to the questionnaires were followed-up two weeks after being emailed 
or faxed, until all responses had been returned. On receipt, incomplete questionnaires were set aside and excluded from the final analysis.

Non-participatory observations of the meetings of 13 PTC meetings followed this between June 2011 and June 2013 in Phase 2. Observations were carried out only in those institutions which gave permission to conduct the study at their site. In total, 26 PTC meetings were observed. This meant that in some PTCs, more than one meeting was observed for the purpose of reaching data saturation. Observed PTC meetings were also typically audio recorded for later transcription, except for a few cases where consent was not given. In these cases, detailed notes were taken of the meeting and proceedings, and later compared with the minutes of the meeting to ensure accuracy and trustworthiness.

The gaps identified in the first two phases were addressed in Phase 3 through non-structured in-depth interviews with nine pharmacy managers who consented to be interviewed between October 2013 and March 2014. Seven of these pharmacists (one from a tertiary hospital and three from district and regional hospitals respectively) were hospital-based and two were from district pharmacies. Two of the interviews were conducted with pharmacy managers whose PTCs were not active. The interviews were conducted in a private room at the participant's facility, were audio recorded for later transcription, and typically lasted approximately 30 minutes

Descriptive statistics were used to summarise Phase 1 survey results, using frequency counts and percentages. Transcribed data from Phases 2 and 3 were analysed using NVivo9®. Data were coded into categories and developed into a framework of themes. Results from the different phases were converged during the interpretation phase. Phase 1 survey results were compared to the themes identified from observations (Phase 2) and interviews (Phase 3) to confirm actual PTC structures and activities.

Ethical clearance for the study was obtained from the Medunsa Research Ethics Committee of the University of Limpopo (now Sefako Makgatho Health Sciences University) (MREC/H/170/2010:PG) and permission granted by provincial authorities. All participants provided written informed consent.

\section{Results}

Table 1 shows the sample for each phase of the study as well as the hospital level of care for the relevant PTC or pharmacist. The overall response rate for the survey in Phase 1 was $76.6 \%$ (23 out of 30 ). Three questionnaires were incomplete and, as mentioned, were subsequently excluded from the data analysis, making a final sample size of 20 . One of the 20 responding pharmacists indicated that their PTC was inactive at the time of the survey; however, some of the responses from this questionnaire were included in the final analysis.

The provincial PTC was not included in Phase 1 as it was inactive at the time of the survey. However at the time of Phase 2, it had been revitalized and consequently was included in Phase 2.

Table 1: $\quad$ Final sample and hospital level of care for each of the three phases of the study

\begin{tabular}{lccc}
\hline Level of care & $\begin{array}{c}\text { Phase 1 Pharmacist } \\
\text { Survey }\end{array}$ & $\begin{array}{c}\text { Phase 2 PTC } \\
\text { Observation }\end{array}$ & Phase 3 Interviews \\
\hline District hospital & 9 & 3 & 3 \\
Regional hospital & 6 & 4 & 3 \\
Tertiary hospital & 2 & 3 & 1 \\
District PTC & 3 & 2 & 2 \\
Provincial PTC & 0 & 1 & - \\
\hline Total & 20 & 13 & 9
\end{tabular}

NB. The provincial PTC was not included in Phase 1, as it was inactive at that stage and in Phase 3, as it was constituted by members who served at lower level PTCs. It was however included in Phase 2, as it had been revitalised at that stage of the study.

As seen in Table 1, in Phase 2 PTC meetings were observed at 13 out of the 20 hospitals, with representation from all levels of care. At some of the hospitals, more than one PTC meeting was observed which resulted in a total of 26 observations. 


\subsection{Quantitative findings - Phase 1}

\subsubsection{Structure of the PTCs}

\subsubsection{Meetings}

PTC meetings in this study varied between monthly to quarterly per year (see Figure 1). Seventy five percent of regional hospitals met once a month and both the tertiary hospitals met once a month. All the other institutions were within the Gauteng provincial specifications [26] as they met once a month or quarterly.

\section{Figure 1: Frequency of PTCs meetings among the various hospitals in Gauteng Province $(n=20)$}

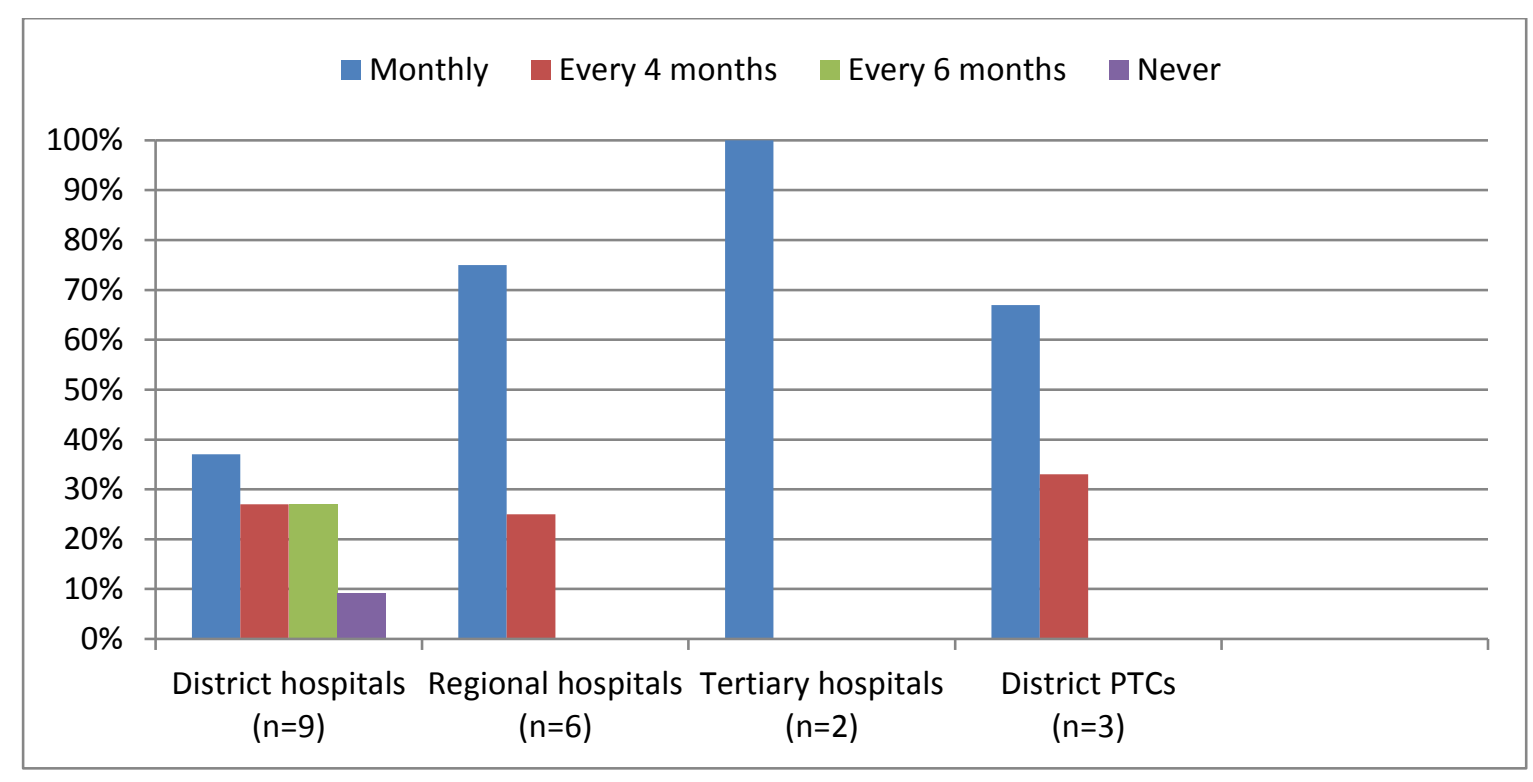

Table 2 shows the categories of professionals represented in the surveyed PTCs. 


\begin{tabular}{lccccc}
\hline $\begin{array}{l}\text { Categories of } \\
\text { professionals }\end{array}$ & $\begin{array}{c}\text { District } \\
\text { Hospital } \\
(\mathbf{n = 9 )}\end{array}$ & $\begin{array}{c}\text { Regional } \\
\text { Hospital } \\
(\mathbf{n}=6)\end{array}$ & $\begin{array}{c}\text { Tertiary } \\
\text { Hospital } \\
(\mathbf{n}=\mathbf{2})\end{array}$ & $\begin{array}{c}\text { District } \\
\text { PTC (n=3) }\end{array}$ & Total (N=20) \\
\hline $\begin{array}{l}\text { Clinical Experts } \\
\begin{array}{l}\text { Specialist } \\
\text { representing the }\end{array}\end{array}$ & 9 & 5 & 2 & 1 & 17 \\
$\begin{array}{l}\text { major disciplines } \\
\text { Clinical }\end{array}$ & 3 & 0 & 2 & 0 & 5 \\
$\begin{array}{l}\text { Pharmacology } \\
\text { Head of Pharmacy }\end{array}$ & 0 & 0 & 0 & 0 & 0 \\
$\begin{array}{l}\text { School } \\
\text { Nursing } \\
\text { representatives }\end{array}$ & 7 & 4 & 0 & 3 & 14 \\
$\begin{array}{l}\text { Clinical } \\
\text { Microbiology } \\
\text { Clinical Directors }\end{array}$ & 1 & 0 & 2 & 1 & 4 \\
$\begin{array}{l}\text { Secretariat } \\
\text { Financial Director }\end{array}$ & 3 & 0 & 2 & 0 & 2 \\
$\begin{array}{l}\text { (or representative } \\
\text { of the finance } \\
\text { department) }\end{array}$ & 6 & 2 & 1 & 2 & 11 \\
\hline
\end{tabular}

Overall, $85 \%$ of the committees had clinical specialists as members. Clinical Directors from academic hospitals were represented in $10 \%$ of the PTCs, with $100 \%$ representation at the tertiary hospital PTCs and no representation at the district PTCs, district hospital and regional hospital PTCs. The tertiary hospital's PTCs were the only ones that did not have representation from nursing, whereas in all the other PTCs nursing was represented in more than $70 \%$ of the committees. Fifty five percent of the pharmacists were the secretariat of their respective committees.

\subsubsection{Subcommittees}

In the survey, pharmacists indicated that four of the 20 PTCs had a formulary subcommittee $(20 \%)$; five (25\%) had an ADR sub-committee, seven (35\%) had an antimicrobial subcommittee, and 18 $(90 \%)$ had infection control subcommittees. Nine hospitals $(45 \%)$ had other subcommittees, which included a blood and blood products committee and a quality assurance committee.

\subsubsection{Activities of PTCs}

The activities of the PTCs are summarised in Table 3. 


\begin{tabular}{|c|c|c|c|c|c|}
\hline ACTIVITIES* & $\begin{array}{l}\text { District } \\
\text { Hospital PTC } \\
(n=9)\end{array}$ & $\begin{array}{l}\text { Regional } \\
\text { Hospital } \\
(n=5)\end{array}$ & $\begin{array}{l}\text { Tertiary } \\
\text { Hospital } \\
(n=2)\end{array}$ & $\begin{array}{l}\text { District PTC } \\
(n=3)\end{array}$ & $\begin{array}{l}\text { Total }(\%)(\mathrm{N} \\
19)\end{array}$ \\
\hline $\begin{array}{l}\text { Dissemination decisions of } \\
\text { the committee to all staff } \\
\text { members }\end{array}$ & 9 & 5 & 2 & 3 & 19 \\
\hline $\begin{array}{l}\text { Formulation of policies and } \\
\text { guidelines pertaining to the } \\
\text { use of medicines within the } \\
\text { hospital }\end{array}$ & 8 & 5 & 2 & 3 & 18 \\
\hline Developing formularies & 9 & 3 & 2 & 2 & 17 \\
\hline $\begin{array}{l}\text { Monitoring of expenditure on } \\
\text { medicines; ensure that it is } \\
\text { in line with current budgets } \\
\text { to maintain rational and } \\
\text { cost-effective prescribing } \\
\text { practices. }\end{array}$ & 7 & 5 & 2 & 3 & 17 \\
\hline $\begin{array}{l}\text { Drafting and coordinating } \\
\text { implementation of treatment } \\
\text { guidelines }\end{array}$ & 6 & 4 & 2 & 2 & 14 \\
\hline $\begin{array}{l}\text { Ensure a proper down } \\
\text { referral system }\end{array}$ & 9 & 3 & 0 & 2 & 12 \\
\hline $\begin{array}{l}\text { Carry out medicine } \\
\text { utilization evaluation }\end{array}$ & 6 & 4 & 1 & 0 & 11 \\
\hline $\begin{array}{l}\text { Develop and enforce } \\
\text { standard guidelines for } \\
\text { company representative }\end{array}$ & 4 & 3 & 2 & 2 & 11 \\
\hline $\begin{array}{l}\text { Supporting research } \\
\text { activities by reviewing } \\
\text { protocols and evaluating } \\
\text { data relating to new } \\
\text { medicines used in the } \\
\text { hospitals }\end{array}$ & 5 & 4 & 2 & 1 & 10 \\
\hline $\begin{array}{l}\text { Review the National } \\
\text { Treatment Guidelines }\end{array}$ & 6 & 2 & 2 & 1 & 11 \\
\hline $\begin{array}{l}\text { Initiation of educational } \\
\text { programmes in matters } \\
\text { relating to drug therapy }\end{array}$ & 6 & 2 & 0 & 2 & 10 \\
\hline $\begin{array}{l}\text { Preparation of new standard } \\
\text { treatment guidelines where } \\
\text { applicable }\end{array}$ & 4 & 1 & 2 & 2 & 9 \\
\hline $\begin{array}{l}\text { Collecting and processing } \\
\text { reports of adverse drug } \\
\text { reactions. }\end{array}$ & 4 & 1 & 1 & 1 & 7 \\
\hline
\end{tabular}

${ }^{*}$ Activities of PTCs as stipulated in Circular 27 [26]

According to the survey, dissemination of PTC decisions to all staff was carried out by all of the PTCs. This was followed by formulation of policies and guidelines performed by $94.7 \%$ of the PTCs, and formulary development and monitoring expenditure on medicines carried out by $89.4 \%$ of the PTCs (Table 3).

The least performed activities were the collection and processing of ADRs and development and enforcement of guidelines for company representatives $(36.8 \%)$.

\subsubsection{Challenges to PTC activity}

Many factors contribute to the success of the PTCs. The challenges encountered by pharmacists in keeping PTCs active are presented in Figure 2. Lack of staff was a challenge encountered by $35 \%$ of the pharmacists, followed by poor attendance of meetings (30\%), poor communication of decisions $(20 \%)$ and lack of time allocated for meetings (20\%). 


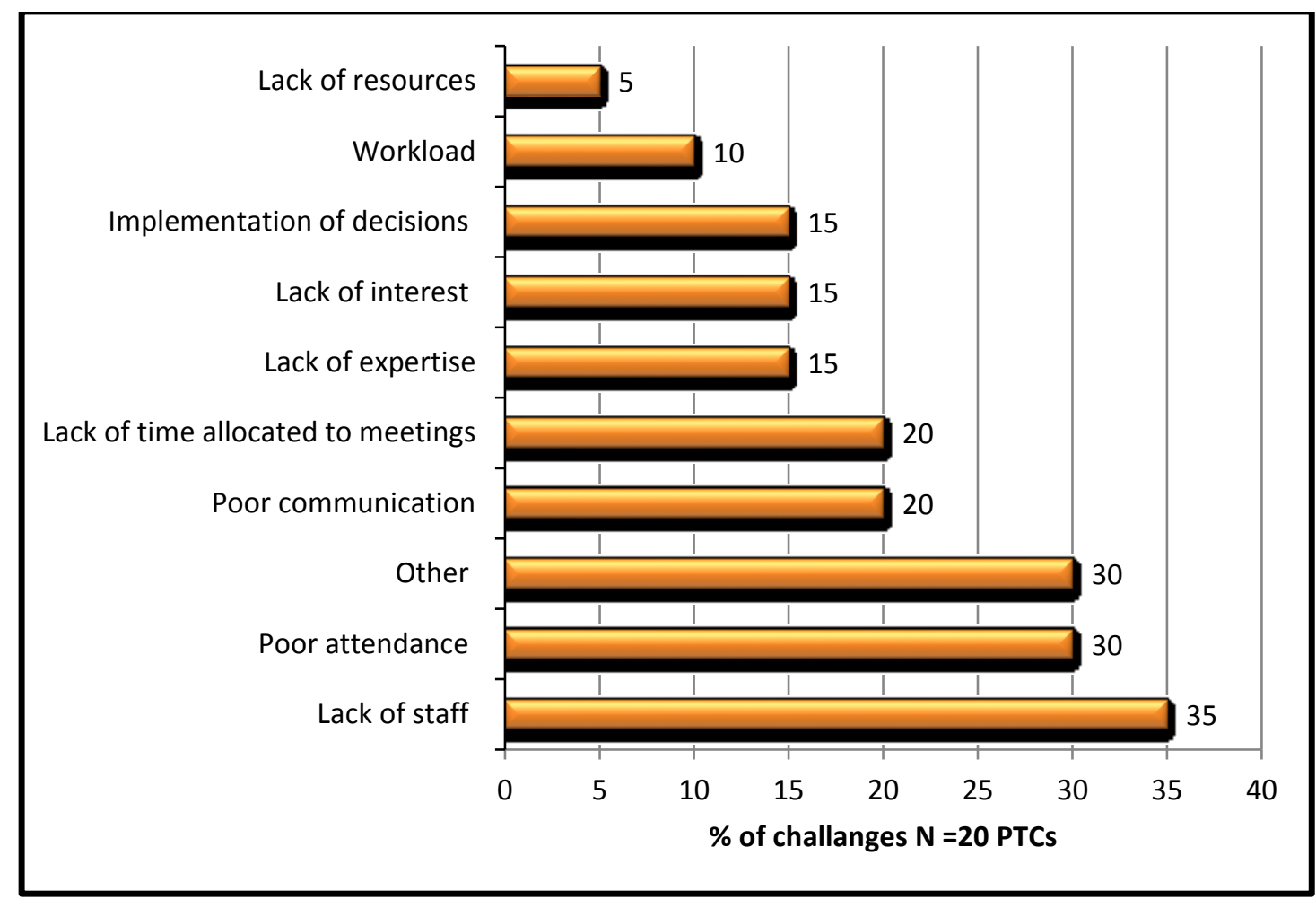

\subsection{Qualitative findings - Phases 2 and 3}

These were derived from observation of 26 PTC meetings and 9 semi- structured interviews.

\subsubsection{Subcommittees}

The only subcommittee which seemed to be active or in the process of being formulated among the PTCs in the study was the antimicrobial stewardship committee, specifically at tertiary level PTCs and only one regional level PTC.

The provincial PTC was the only committee that had active subcommittees, which were observed to be (1) Safety and Quality Subcommittee and ADR reports, (2) Medicine Rational Utilisation Subcommittee, (3) Formulary Subcommittee, and (4) Procurement Advisory Subcommittee. In addition to the formal subcommittees as observed, two other programmes namely the National Health Laboratories (NHLS) and Expanded Programme on Immunisation (EPI) were represented during PTC meetings, especially the district PTCs and in one district hospital. These two programmes featured at PTC meetings for various reasons. One of the pharmacists in Phase 3 of the study explained that the presence of the NHLS was to contain the costs of laboratory services:

"The laboratory and blood services were no part of the PTC previously but a directive to incorporate them into the PTC came from the province. I think there were a lot of challenges in terms of blood tests done at different levels with respect to cost, monitoring of expenditure, and appropriate blood tests for appropriate level of care". [District pharmacist]

\subsubsection{Activities of PTCs}

Pharmaceutical budgets were discussed at all observed PTC meetings. The main discussions revolved around budget allocation which was deemed to be inadequate in most instances:

"The fact that pharmacy managers never receive amounts they request for their budget was seen as a challenge. Although the requested budget is not allocated pharmacy is still expected to deliver a service of high quality". [Observation Provincial PTC]

In contrast to the survey results, it was evident during the observations of PTC meetings that formulary management was carried out in all (13) PTCs. It was also evident that more than half of the 
PTCs reviewed their formulary lists on a regular basis. Other discussions dealt with the rationale for the addition of new medicines, which was typically based on their costs and the clinical evidence. Five of the PTCs approved the addition of new medicines into their formularies, and removed some medicines from the formulary during the observed meetings. Variation in the application and/ or motivation for the addition of new medicines at the different institution was also observed.

In addition to formulary management, management of medicine shortages was observed to be the second highest activity which the PTCs were involved with, as this was on the agendas of all PTCs with the exception of the Provincial PTC.

The PTCs also appeared actively involved with $A B C$ analysis of priority areas to concentrate on in line with WHO recommendations [23], i.e. the top 20 medicines with the highest expenditure. ABC analysis is a well accepted method for prioritising key medicines to concentrate on based on their annual usage and costs [28], with ' $A$ ' referring to high cost items, ' $B$ ' referring to medium cost items and ' $C$ ' referring to low cost items. An $A B C$ analysis was used as a basis to carry out medicine utilisation reviews in at least one of the PTCs, as illustrated by the discussion:

"We have done that (MUE) on the use of antibiotics, because antibiotic use is very high; third line antibiotics often appear in the top ten items of our ABC analysis because they are expensive". [tertiary hospital pharmacist]

\subsubsection{Formularies}

Four of the nine pharmacists interviewed indicated that they did not have a hospital specific formulary list or manual. All of these pharmacists indicated that they used the current South African EML as a point of reference, as illustrated by the pharmacist at a district hospital:

"Our formulary is guided by the EML, so we take the EML as our formulary. If the doctors ask for an item, we first check if it is an EML item. If it is, we know that we have to keep it". [District pharmacist]

However, it was not evident how dissemination of the PTC decisions was carried out (Phase 2 and 3). During the Phase 3 interviews, pharmacists indicated that this was typically undertaken through circular letters or personal communication by the committees' members. From the observations (Phase 2), it was evident that ADR reporting was indeed poor since in most PCT meetings, despite typically being on the agenda, no reports were presented.

\subsubsection{Challenges to PTC activity}

Follow-up interviews confirmed that the lack of staff and competing priorities of PTC members, which also contributed to the poor attendance at PTC meetings:

"The biggest challenge is competing priorities, other meetings, training and I think a big gap for us is that there is a lack of doctors." [Regional hospital pharmacist]

Potential reasons included the high turnover of staff. In addition the lack of support of the committees from clinicians due to other commitments:

"There are a lot of meetings and if you have to have all those doctors in all meetings it would not be possible". [Regional hospital pharmacist]

"The PTC was not compliant, for example, there was no representative of the doctors, and we did not get any response from the district medical officer". [District hospital pharmacist]

The lack of expertise in pharmacoeconomics and evidence-based decision-making was also identified as one of the challenges in formulary management. Survey results and interviews with pharmacists revealed that insufficient staff and poor attendance of meetings hindered PTC activities.

\section{Discussion}

The study highlighted variations among the different PTC levels in the way they were structured, and in their approaches to formulary management. Concerns are important to address given the high prevalence of infectious diseases as well as non-communicable diseases in South Africa, including hypertension and obesity, which is growing adding to the cost public health cost burden [29-34]. Encouragingly, the activities of the PTCs in the Gauteng Province were similar to the stipulations in both WHO [23] and the Provincial Guidelines [24]. However, concerns in a number of areas which need to be addressed. 


\subsection{Meetings}

Encouragingly, the majority of PTCs met on average once monthly. This compares with typically lower rates in a number of other countries, e.g. $37.5 \%$ of PTCs met quarterly and only $25 \%$ met monthly among Sudanese hospitals [14]. In Spain, there was a mean of 5.1 meetings per year [21], in Denmark two to six per year [20], and in Canada 8.2 times a year on average in hospitals with 300 or more beds [21].

However, there was limited representation by clinical directors in the PTCs, which could be attributed to the fact that the survey asked for clinical directors of academic hospitals, which were only represented by two hospitals. Clinical Microbiology was represented in $20 \%$ and clinical pharmacologists in $25 \%$ of the PTCs, which was similar to hospital PTCs in the Netherlands. However, Clinical Pharmacologists play a greater role among DTCs in Stockholm County in Sweden $[3,35]$. When considering a specific level of care, both tertiary hospitals had representation from clinical pharmacologists, which is important to train specialists.

Studies conducted in Denmark and the Netherlands showed that nurse representation was much lower compared to this study (70\%) and varied from $7 \%$ to $29 \%$ of hospital PTCs [20]. Low representation was also seen in Thailand [36].

In this study, positions held by pharmacists were seen in all the PTCs, which is in line with the provincial guidelines. This is important as they are trained to provide expert advice on the evaluation of new medicines alongside clinical pharmacologists. They are also knowledgeable in areas such as therapeutic equivalence and they are often responsible for managing the medicines budget [21].

\subsection{Subcommittees}

PTCs often have subcommittees to address particular issues and assist with the complexities of decision making $[23,37]$. The antimicrobial stewardship committee was the most active subcommittee in our study (35\%). This is encouraging given concerns with the extent of antimicrobial resistance (AMR) in hospitals in South Africa and the recent Department of Health initiatives to reduce AMR $[38,39]$. Most hospitals $(45 \%)$ also had other subcommittees in addition to those stipulated in the Provincial guidelines.

Studies on the structure and operation of PTC in other countries also indicated that in some hospitals PTCs worked alongside other committees [20,40].

\subsection{Activities}

Formulary management was observed to be the main activity carried out by all PTCs. This is welcomed as South Africa has developed treatment guidelines that can be used when developing hospital formularies [24]. This is similar to a national survey in the US where $99.6 \%$ of hospitals and health-system PTCs were responsible for formulary development and management including drug policy development [41], with similar findings in other studies [9,14, 42].

Even though dissemination of PTC decisions was indicated as one of the main activities of the PTCs in Phase 1 (Table 3), this was not evident from Phase 2. This was also seen by Tan et al. [43], who upon reviewing PTC minutes, found no action appeared to be taken to implement or follow up on some PTC decisions. This is a concern as inadequate dissemination of information leads to a loss of credibility and limited effectiveness of PTCs.

The second activity that PTCs were mostly involved with was the management of medicine shortages. This is a concern since according to WHO [23], a PTC often has to coordinate with those responsible for procurement and distribution of medicines to help ensure patients have access to the most appropriate medicines. Efforts should be made to avoid PTCs becoming a forum for only making procurement decisions and managing stock outs [23]. Having said this, shortages should be part of the agenda for PTCs [23], with PTCs developing contingency plans to prepare for possible prolonged shortages as part of good medicine management. This can be part of monitoring of expenditure and medicine use, with expenditure monitoring carried out by $89 \%$ of the PTCs in this study with 
discussions on budget allocation and expenditure taking place in five of the observed 13 PTC meetings.

The main concern at all PTCs was insufficient funding for medicines, similar to other countries [42]. The current trend in budgeting is to decentralise budgets down to the point of service, since those rendering the service are usually more aware of specific circumstances and conditions, as seen across countries despite concerns [44-46]. However, this approach had not yet been adopted by the Province, with almost all levels of PTCs complaining about their lack of involvement in determining budget allocation.

Aggregate drug utilisation data can be used to conduct $A B C$ analysis and therapeutic category analysis to help PTCs better manage their formulary medicines list and identify problems [23]. This is also a concern since in our study only three PTCs in Phase 2 were undertaking such activities.

PTCs also have a major role in ensuring that all medicines are prescribed, dispensed and administered to patients in as safe a way as possible, and that all medicines are of adequate quality. As a result, help to ensure appropriate use of resources. Consequently, one of the functions of PTCs should be to oversee the monitoring, tracking and accounting of adverse drug reactions as documented in the Guateng Province guidelines $[24,26]$. However in this study, one of the least performed activities was the collection and processing of ADRs, similar to other countries and settings [47]. This is a concern as evidence of a clear pharmacovigilance system to monitor and manage ADRs is a requirement for compliance with the National Core Standards [48]. Measures to increase ADR reporting include education of health professionals of its importance, reporting forms being readily available and the use of electronic reporting, which have all been found to be effective elsewhere [48-50], and have shown to be a possibility among public hospitals in South Africa [51].

Overall, the success of a PTC depends upon it being active and working regularly in a consistent direction [23]. However, poor communication of decisions and lack of time allocated for meetings were seen in our study. Lack of expertise on applying evidence-based decision-making in formulary management was also identified as one the main challenges among PTCs, similar to other countries $[9,22,52]$. The lack of expertise can be addressed by bringing together various specialists from different disciplines to compile suggested medicines for different disease states, building on experiences in other countries [3,35]. In this way, PTCs become a learning organisation to benefit the hospital in the future.

We believe the mixed method approach to data collection in our study enable the principal researcher (MM) to explore the activities and functions of PTCs in Gauteng Province in detail as well as the challenges of keeping PTCs active. We also believe the sample of hospitals chosen was representative of the wide spectrum of PTC levels in the Province adding robustness to our findings and suggested future activities. Future programmes should strengthen PTCs in specialised aspects of formulary management, building on the replies of the participants. This includes pharmacoeconomics in addition to evidence based medicine. Strong institutional support should be encouraged, along with adequate funding, to ensure better participation in PTC activities to enhance rational medicines use among public sector hospitals in South Africa. This acknowledges that membership of PTCs is typically voluntary and members generally have several other roles [23]. However, appropriate management of medicines should be the responsibility of all to ensure good use of available resources with ever growing pressure on resources in South Africa. Resources should also be made available to support auditing of the PTCs activities, which can involve the development of an indicator checklist.

We are aware that we only undertook this study in one Province in South Africa. However, we believe in view of the comprehensive approach we adopted and the careful choosing of the Province that the findings will be applicable to other hospitals in South Africa. We will be following this up in future research.

\section{Conclusion}

We believe this is the first study in South Africa that has looked at the structure, activities and functions of PTCs in public hospitals. Positively PTCs in the public hospitals in South Africa were active in the majority of the hospitals, with their structure and activities similar to the stipulations from 
both WHO and the Provincial Guidelines, which is encouraging. Their main activities evolved around formulary management, with variation among the different levels of care, with the tertiary and provincial hospitals using more evidence based approaches when selecting medicines for the formulary. However challenges exist including adequate resourcing, undertaking drug utilisation activities to monitor and improve medicine use, lack of ADR reporting and the lack of expertise in evidence based decision making. These are opportunities to strengthen PTC activities and functions in South Africa by learning from other countries. Similar studies can be carried out in other Provinces in South Africa to assess the generalizability of our findings. Other studies should also be undertaken to explore the areas of concern in our study particularly around promoting and ensuring the rational use of medicines. We will be monitoring this in the future.

Key points:

- There are a number of possible functions of PTCs. The National Drug Policy in South Africa has as an objective that PTCs should be established in all hospitals the rational and efficient use of medicines as well as cost-effective supply

- There have been a number of guidelines in South Africa to enhance the rational use of medicines including guidance on PTC activities. However despite this, the structure and function of PTCs in Gauteng Province varied greatly

- Pharmacists were typically involved in PTC activities, with principal activities of PTCs involving formulary management and dissemination of decisions

- Identified concerns included current budget allocation, lack of ADR and medical error reporting as well as a lack of evidence-based decision making

\section{Acknowledgments}

We thank the Gauteng Department of Health for allowing us to collect data, the various institutions and the pharmacists who agreed to participate in this project. We would also like to thank the management of University of Limpopo for the Teaching and Development Grant which was awarded to Moliehi Matlala to complete her data collection and write up of the $\mathrm{PhD}$ thesis which was the basis of the paper.

The study authors have no conflicts of interest to declare.

\section{References}

( ${ }^{*}$ of importance, ${ }^{* *}$ of considerable importance)

1. Bertino, J. Pharmacy and therapeutic committees and hospital formulary. In Waldman S.A and, Terzic A. Pharmacology and Therapeutics Principles to practice. 2009; 1233-1236. USA. Saunders ELSIEVIER

2. Godman B, Malmstrom RE, Diogene E, Gray A, Jayathissa S, Timoney A, et al. Are new models needed to optimize the utilization of new medicines to sustain healthcare systems? Expert review of clinical pharmacology. 2015;8(1):77-94.

3. Bjorkhem-Bergman L, Andersen-Karlsson E, Laing R, Diogene E, Melien O, Jirlow M, et al. Interface management of pharmacotherapy. Joint hospital and primary care drug recommendations. European journal of clinical pharmacology. 2013;69 Suppl 1:73-8.

( ${ }^{*}$ Demonstrating joint activities of PTCs to enhance the rational use of medicines across sectors)

4. Spurling GK, Mansfield PR, Montgomery BD, Lexchin J, Doust J, Othman N, et al. Information from pharmaceutical companies and the quality, quantity, and cost of physicians' prescribing: a systematic review. PLoS medicine. 2010;7(10):e1000352.

5. Civaner M. Sale strategies of pharmaceutical companies in a "pharmerging" country: the problems will not improve if the gaps remain. Health policy. 2012;106(3):225-32.

6. Fleischman W, Agrawal S, King M, Venkatesh AK, Krumholz HM, McKee D, et al. Association between payments from manufacturers of pharmaceuticals to physicians and regional prescribing: cross sectional ecological study. BMJ. 2016;354:i4189.

7. Perlis RH, Perlis CS. Physician Payments from Industry Are Associated with Greater Medicare Part D Prescribing Costs. PloS one. 2016;11(5):e0155474.

8. Salmasi S, Ming LC, Khan TM. Interaction and medical inducement between pharmaceutical representatives and physicians: a meta-synthesis. Journal of pharmaceutical policy and practice. 2016;9(1):37

9. Lima-Dellamora E, Caetano R, Gustafsson LL, Godman B, Patterson K, Osorio-de-Castro CGS. An Analytical Framework for Assessing Drug and Therapeutics Committee Structure and Work 
Processes in Tertiary Brazilian Hospitals. Basic \& Clinical Pharmacology \& Toxicology. 2014; 115:268-276

10. Hoffmann M. The right drug, but from whose perspective? A framework for analyzing the structure and activities of drug and therapeutics committees. European Journal of Clinical Pharmacology 2013; 69 (1): S79-87.

( ${ }^{*}$ Good paper examining the structure and function of PTCs)

11. Godman B, Wettermark B, Hoffmann M, Andersson K, Haycox A, Gustafsson LL. Multifaceted national and regional drug reforms and initiatives in ambulatory care in Sweden: global relevance. Expert review of pharmacoeconomics \& outcomes research. 2009;9(1):65-83.

12. Laing RO, Hogerzeil HV, Ross-Degnan, D. Ten recommendations to improve the use of medicines in developing countries. Health Policy and Planning. 2001; 16 (1): 13-20.

13. Weekes LM, Brooks C. Drug and Therapeutics Committees in Australia: expected and actual performance. British Journal of clinical pharmacology. 1996; 42: 551-557.

14. Sabah BA, Sania AS, Salah IK. 2012. Assessment of structure, implementation and activities, Hospital formulary System in Khartoum State Hospitals. Journal of Pharmaceutical and Biomedical Science.2012; 22 (22); 1-6

15. Malmstrom RE, Godman BB, Diogene E, Baumgartel C, Bennie M, Bishop I, et al. Dabigatran - a case history demonstrating the need for comprehensive approaches to optimize the use of new drugs. Frontiers in pharmacology. 2013;4:39.

16. Godman B, Campbell S, Suh HS, Finlayson A, Bennie M, Gustafsson L. Ongoing measures to enhance prescribing efficiency across Europe: implications for other countries. J Health Tech Assess 2013;1:27-42.

17. World Health organization (WHO). 2007. The 60 th World Health Assembly Report. Geneva. Available at URL: http://apps.who.int/gb/ebwha/pdf_files/WHASSA_WHA60-Rec1/E/cover-intro-60en.pdf

18. American Society of Health-System Pharmacists (ASHP). Guidelines on the pharmacy and therapeutics committees and the formulary system. American Journal of Health-Systems Pharmacy. 2008; 65: 1272-83.

19. Mittman N, Knowels S. A Survey of Pharmacy and Therapeutics Committees across Canada: Scope and responsibilities. Canadian Journal of Clinical Phamacology. 2009; 16 (1): e171-179. 20. Plet HT, Hallas J, Nielsen GS, Kjeldsen LJ. Drug and therapeutics committees in Danish hospitals: a survey of organization, activities and drug selection procedures. Basic \& clinical pharmacology \& toxicology. 2013;112(4):264-9

21. Puigventos F, Santos-Ramos B, Ortega A, Duran-Garcia E. Structure and procedures of the pharmacy and therapeutics committees in Spanish hospitals. Pharm World \& Science. 2010; 32 (6) 767-75.

22. Vang C, Tomson G, Kounnavong S, Southammavong T, Phanyanouvong A, Johansson R, et al. Improving the performance of Drug and Therapeutics Committees in hospitals--a quasi-experimental study in Laos. European journal of clinical pharmacology. 2006;62(1):57-63

23. Holloway K, Green T. Drug and Therapeutics Committees: A practical guide. World Health Organisation 2003. Available at URL: http://apps.who.int/medicinedocs/pdf/s4882e/s4882e.pdf (** Good practical guide to suggested PTC activities)

24. Gauteng Province Department of Health. 2013. Guidelines for Implementation of Pharmaceutical and Therapeutics Committee in Gauteng Province. 1st edition. Available at URL:

http://apps.who.int/medicinedocs/documents/s21654en/s21654en.pdf

(**Important document outlining PTC activities in the Province)

25. Department of Health. 1996. National Drug Policy for South Africa. Available at URL:

http://apps.who.int/medicinedocs/documents/s17744en/s17744en.pdf

26. Gauteng Province Department of Health. 2004. Implementation of pharmacy and therapeutics committees at all levels. Circular Letter 27. Available in URL:

http://www.treasury.gov.za/publications/annual\%20reports/provincial/2005/GT/GP\%20$\% 20$ Vote $\% 2004 \% 20-\% 20$ Health.pdf

27. Republic of South Africa. White paper on National Health Insurance for South Africa: Towards universal coverage. National Department of Health. Government Gazzette No 39506: version 40. 11 December 2015.

28. Rankin J. Analyzing and controlling pharmaceutical expenditure. Chapter 40 in: MDS-3: Managing Access to Medicine and Health Technologies. Arlington, VA: Management Sciences for Health. 2012. 29. Naidoo S, Wand H, Abbai NS, Ramjee G. High prevalence and incidence of sexually transmitted infections among women living in Kwazulu-Natal, South Africa. AIDS Res Ther. 2014 Sep 15; 11:31 
30. Ramjee G, Abbai NS, Naidoo S. Women and Sexually Transmitted Infections in Africa. Open Journal of Obstetrics and Gynecology 2015; 5: 385-399

32. Maimela E, Alberts M, Modjadji SEP, Choma SSR, Dikotope SA, Ntuli TS, Van Geertruyden J, The Prevalence and Determinants of Chronic Non-Communicable Disease Risk Factors amongst Adults in the Dikgale Health Demographic and Surveillance System (HDSS) Site, Limpopo Province of South Africa. PloS ONE, 2016; e0147926. doi:10.1371

32. Lalkhen $\mathrm{H}$, Mash R. Multimorbidity in non-communicable disease in South African primary healthcare. South African Medical Journal 2015; 105 (2). Available from:

http://www.Scielo.org.za/pdf/samj/v105n2/24pdf.

33. Lloyd-Sherlock P, Beard J, Minicuci N, Ebrahim S, Chatterji S. Hypertension among older adults in low- and middle-income countries: prevalence, awareness and control. International Journal of Epidemiology. 2014; 1-13

34. Cois A, Day C. Obesity trends and risk factors in the South African adult population. BMC obesity. 2015;2:42.

35. Gustafsson LL, Wettermark B, Godman B, Andersen-Karlsson E, Bergman U, Hasselstrom J, et al. The 'wise list'- a comprehensive concept to select, communicate and achieve adherence to recommendations of essential drugs in ambulatory care in Stockholm. Basic \& clinical pharmacology \& toxicology. 2011;108(4):224-33.

( ${ }^{*}$ Good paper demonstrating high adherence to recommended medicines due to robust systems in place and trust in the formulary)

36. Ummmuaypornlert A, Kiitikannakorn N. Performance of Pharmacy and Therapeutics Committees of Public Hospitals in Rural Thailand. Mahidol University Journal of Pharmaceutical Sciences. 2014; $41(1), 11-18$

37. Olson C. Treatment guidelines and formulary manuals. Chapter 17 in: MDS-3: Managing Access to Medicine and Health Technologies. Arlington, VA: Management Sciences for Health. 2012

38. Mendelson M, Matsoso M. The South African Antimicrobial Resistance Strategy Framework. AMR Control. 2015:54-61

39. South Africa Department of Health. 2015. Implementation plan for the antimicrobial resistance strategy framework in South Africa: 2014-2019. Available at URL:

http://www.google.co.uk/url?sa=t\&rct=j\&q=\&esrc=s\&source=web\&cd=1\&ved=0ahUKEwjkq9O24IrRAh WJNIAKHb7qAgUQFggaMAA\&url=http\%3A\%2F\%2Fwww.health.gov.za\%2Findex.php\%2Fantimicrob ial-resistance\%3Fdownload\%3D1175\%3Aimplementation-plan-for-the-antimicrobial-resistancestrategy-framework-in-south-africa-2014-2019\&usg=AFQjCNHKDUEmdzqyeLB-i-ZMnz6W0xDaA\&bvm=bv.142059868,d.ZWM

40. Duran-Garcia E, Santos-Ramos B, Puigventos-Latore F, Ortega A. Literature review on the structure and operation of Pharmacy and Therapeutics Committees. International Journal Clinical Pharmacy 2011; 33: 475-482.

( ${ }^{*}$ Good background paper on the structure and function of PTCs)

41. Pedersen CA, Schneider PJ \& Scheckelhoff GJ. ASHP national survey of pharmacy practice, hospital setting: Prescribing and transcribing. American Journal of Health-Systems Pharmacy. 2005; 62: 378-90.

42. Collao J.F, Smith F and Barber N. Selection of Medicine in Chilean public hospitals: an exploratory study. BMC Health Services Research. 2013; 13 (10). Available at http://www.biomedicalcentral.com/1472-6963/13/10

43. Tan EL, Day RO, Brien JE. Drug and Therapeutics Committees- are they fulfilling their potential to improve the quality use of medicines? International Journal of Pharmacy Practice 2003; 11:175-181. 44. Spitzer-Lehamann R. 1994. Nursing Management Desk Reference: Concepts, Skills and Strategies. Philadephia:W.B. Saunders.

45. Walsh K. Managing the budget in healthcare professional education. Annals Medical Healthcare Science Research. 2016; 6(2): 71-73. doi:

46. Matusewicz W, Godman B, Pedersen HB, Furst J, Gulbinovic J, Mack A, et al. Improving the managed introduction of new medicines: sharing experiences to aid authorities across Europe. Expert review of pharmacoeconomics \& outcomes research. 2015;15(5):755-8.

47. Wettermark B, Pehrsson A, Juhasz-Haverinen M, Veg A, Edlert M, Tornwall-Bergendahl G, et al. Financial incentives linked to self-assessment of prescribing patterns: a new approach for quality improvement of drug prescribing in primary care. Quality in primary care. 2009;17(3):179-89 48. Terblanché A, Meyer J, Summers RS. Baseline data for the development and evaluation of a structured pharmacovigilance system in Sebokeng Hospital, Gauteng Province. MURIA Conference Anti Infectives. 2016: 5. PV, NCD, DU Studies. Available at URL: http://muria.nmmu.ac.za/2ndMURIA-Training-Workshop-and-Symposium,-25-27-J 
49. Ortega A, Aquinaqalde A, Lacasa C, Aquerreta I, Fernandez-Bernitez M, Fernandez LM. Efficacy of an adverse drug reaction electronic reporting system integrated into a hospital information system. Annals of Pharmacotherapy. 2008; 42 (10):1491-6.

50. Yen Yu-Hsuan, Kuo Li-Na, Hsu Min-Huei, Li Yu-chuana, Cheng Kuei-Ju. Evaluation of the Electronic Adverse Event Management System. Journal of Experimental and Clinical Medicine. 2010; 2 (6): 287-291.

51. Terblanché A, Meyer JC, Summers RS, Godman B. Impact of a pharmacist-driven pharmacovigilance system in a secondary hospital in the Gauteng Province of South Africa. MURIA 3 2017; 25. Available at URL:

http://muria.mandela.ac.za/muria/media/Store/documents/Abstract\%20book\%20\%20MURAI\%203/MURIA3-AbstractBook-July-2017.pdf

52. Suh D, Opara IR, Agnese WB, Toscani M. Appplication of pharmacoeconomics to formulary decision making in managed care organizations. Am J Manag Care. 2002; 8:161-9 